\title{
Midterm results after endovascular treatment of acute, complicated type B aortic dissection: The Talent Thoracic Registry
}

\author{
Marek P. Ehrlich, MD, ${ }^{\mathrm{a}}$ Herve Rousseau, MD, ${ }^{\mathrm{b}}$ Robin Heijmen, MD, ${ }^{\mathrm{c}}$ Philippe Piquet, $\mathrm{MD},{ }^{\mathrm{d}}$ \\ Jean-Paul Beregi, MD, ${ }^{\mathrm{e}}$ Christoph A. Nienaber, MD, ${ }^{\mathrm{f}}$ Gottfried Sodeck, MD, ${ }^{\mathrm{g}}$ and Rossella Fattori, $\mathrm{MD}^{\mathrm{h}}$
}

Objective: To assess the efficacy and midterm results of endovascular treatment of acute complicated type B dissection.

\begin{abstract}
Methods: From January 1998 to March 2004, 29 patients (7 women and 22 men) with acute complicated aortic type B dissection (mean age, 61 years; range, 22-78), defined as aortic rupture, malperfusion, intractable pain, or uncontrolled hypertension, underwent endovascular stent graft placement with the Medtronic Talent device. Five patients $(17 \%)$ had undergone previous surgery on the ascending aorta and/or aortic valve. The mean aortic diameter at intervention was $48 \pm 13 \mathrm{~mm}$. Follow-up was $100 \%$ complete and averaged $53 \pm 41$ months.

Results: The technical feasibility and success with deployment proximal to the entry tear was $100 \%$, requiring partial or total coverage of the left subclavian artery in only 1 patient (3\%). Hospital mortality was $17 \% \pm 7 \%$ (70\% confidence limit) with 6 late deaths. The causes of hospital death included multiorgan failure in 2 patients, aortic rupture in 2, and retrograde dissection in 1 patient. Three patients $(10 \%)$ who survived the procedure developed neurologic complications ( 2 strokes and 1 transient ischemic attack). One patient required early conversion to surgery because of retrograde type A dissection. Furthermore, 4 patients developed a type Ia endoleak. A postprocedural increase in the distal aortic diameter was observed in 3 patients. The actuarial survival at 1 and 5 years was $79 \%$ and $61 \%$, respectively. Freedom from treatment failure at 1 and 5 years (including reintervention, aortic rupture, device-related complications, aortic-related death, or sudden, unexplained late death) was $82 \%$ and $77 \%$, respectively.
\end{abstract}

Conclusions: Endovascular stent graft placement in acute complicated type B aortic dissection proves to be a promising alternative therapeutic treatment modality in this relatively difficult patient cohort. Refinements, especially in stent design and application, could further improve the prognosis of patients in this lifethreatening situation. (J Thorac Cardiovasc Surg 2013;145:159-65)

Acute aortic dissection of the descending aorta is still a lifethreatening condition with high mortality and morbidity and remains a formidable challenge for cardiac surgeons, as well as, in recent years, interventional radiologists. The optimal management of these patients remains a matter of ongoing debate. ${ }^{1,2}$ In cases of uncomplicated aortic type B dissection, medical treatment controlling hypertension and pain in the initial phase remains the primary

\footnotetext{
From the Department of Cardiothoracic Surgery, ${ }^{\mathrm{a}}$ University Hospital Vienna,

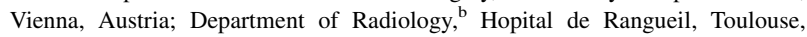
France; Department of Cardiothoracic Surgery, ${ }^{\mathrm{c}}$ St. Antonius Hospital, Nieuwegein, The Netherlands; Hopital Sainte Marguerite, ${ }^{\mathrm{d}}$ Marseille, France; Hopital Cardiologique CHRU, ${ }^{\mathrm{e}}$ Lille, France; Division of Cardiology, ${ }^{\mathrm{f}}$ University Hospital Rostock, Rostock, Germany; Department of Internal Medicine, ${ }^{\mathrm{g}}$ Rudolfstiftung, Vienna, Austria; and Cardiovascular Radiology, ${ }^{\text {h }}$ University Hospital S. Orsola, Bologna, Italy.

Disclosures: Authors have nothing to disclose with regard to commercial support. Received for publication May 31, 2011; revisions received Sept 22, 2011; accepted for publication Oct 5, 2011; available ahead of print Feb 13, 2012.

Address for reprints: Marek P. Ehrlich, MD, Department of Cardiothoracic Surgery, University of Vienna, Währinger Gürtel 18-20, Vienna A-1090 Austria (E-mail: marek.ehrlich@meduniwien.ac.at).

$0022-5223 / \$ 36.00$

Copyright (C) 2013 by The American Association for Thoracic Surgery doi:10.1016/j.jtcvs.2011.10.093
}

treatment option. ${ }^{3}$ Conventional resection and graft replacement of the descending thoracic aorta has been the preferred method of treatment only in cases with complications such as aortic rupture, malperfusion of end organs, and/or persistent pain despite medical treatment but was associated with high morbidity and mortality rates despite improved surgical techniques, intraoperative monitoring of somatosensory evoked potentials and spinal fluid drainage. ${ }^{4,5}$ Contemporary mortality rates after surgical resection of acute complicated type B dissection range from $15 \%$ to $30 \%$ and even exceed $50 \%$ in complicated cases under emergency conditions. ${ }^{6}$ Furthermore, the afflicted population is usually older age and present to surgery with various comorbidities, such as hypertension, obstructive pulmonary disease, and coronary heart disease, all of which have significant effects on the surgical outcome. In the past $2 \mathrm{de}-$ cades, many groups have started to investigate the feasibility of thoracic aortic aneurysmal repair with endovascular stent grafts for various aortic pathologic conditions. ${ }^{7-10}$ During the past decade, endovascular techniques have revolutionized the management of descending thoracic aortic disease, with the benefit of the exclusion of the pathologically altered aorta without direct surgical 


\section{Abbreviation and Acronym \\ TTR $=$ Talent Thoracic Registry}

exposure. Therefore, endovascular stent grafts could offer an attractive and safer alternative approach for treating such special aortic pathologic conditions such as complicated acute type B dissections. ${ }^{11}$ The Talent Thoracic Registry (TTR) was designed to collect outcomes data from patients who underwent endoluminal treatment with the Medtronic Talent thoracic stent graft (Medtronic/AVE, Santa Rosa, Calif) in 7 European referral centers, and the short-term results were reported. ${ }^{12}$ The present subanalysis of the TTR comprises only data from patients who underwent endovascular stent graft placement for acute complicated type B aortic dissections.

\section{METHODS \\ Enrollment}

The present analysis from the TTR registry focused on 29 consecutive patients ( 7 women and 22 men) with acute complicated aortic type B dissection (mean age, 61 years; range, 22-78), defined as aortic rupture, malperfusion, intractable pain, or uncontrolled hypertension who underwent endovascular repair with the Talent Thoracic stent graft from November 1996 to March 2004. This subgroup represents $6 \%$ from a total of 457 cases with thoracic aortic pathologic features collected for the TTR registry. Seven European referral centers (Bologna, Italy; Lille, France; Marseille, France; Nieuwegein, The Netherlands; Rostock, Germany, Toulouse, France; and Vienna, Austria) provided data from patients treated consecutively, with a minimum of 1 year of follow-up. The TTR was approved by the local ethical committee of each participant center. Follow-up analysis was formed on clinical and imaging findings until the last visit and included all adverse events. Data were collected on case report forms and checked for inconsistencies. In the case of discrepancies, the attending investigator was queried to ensure appropriate interpretation of the events.

\section{Patient Characteristics}

An American Society of Anesthesiologists classification greater than class IV was present in $72 \%$ of all cases (Table 1). Five patients $(17 \%)$ had undergone previous aortic surgery. Comorbid medical conditions included hypertension in $25(86 \%)$, coronary artery disease in $8(27 \%)$, and chronic obstructive pulmonary disease in $4(14 \%)$. One of the treated patients had Marfan syndrome.

In 7 patients $(24 \%)$, the dissections extended only into the descending aorta, in 5 patients $(17 \%)$ to the celiac axes, in $5(17 \%)$ into the aortic bifurcation, and in 12 patients $(41 \%)$ into the iliac arteries (Table 2). The indication for stent graft placement was persistent ongoing pain for longer than 72 hours despite aggressive pain medication in 5 patients, refractory hypertension in 2 patients, rupture in 5 patients, and malperfusion in 17 patients (Table 2).

\section{Device Description}

The Talent Thoracic stent graft is composed of Dacron graft fabric supported by self-expanding nitinol springs. The springs are sewn to the graft material with polyester sutures. The graft material is a sheet of monofilament polyester with a seam joining the edges to create a cylindrical tube. The connecting bar provides columnar strength to the device and facilitates deployment. All Talent stent grafts in the study had uncovered springs proximally, and the smallest graft size was $22 \mathrm{~mm}$.

\section{Preintervention Imaging}

Before endovascular treatment, all patients were examined by at least 1 tomographic imaging modality (Figure 1). Computed tomography or magnetic resonance imaging was preferred. In some specific cases, angiography or transesophageal echocardiography was also performed. Contrastenhanced computed tomography was the most frequently used diagnostic method $(95 \%)$, followed by angiography $(37 \%)$, transesophageal echocardiography $(17 \%)$, and magnetic resonance imaging (5\%). All operations were performed with the patient under general anesthesia in the radiology suite under fluoroscopy control by a $\mathrm{C}$-arm image intensifier. The technique of stent graft insertion has been previously reported. ${ }^{12}$

\section{Definitions}

Procedural success was defined as successful deployment of the stent graft device. Primary success was defined as complete exclusion of the injured side without any additional intervention. Secondary success was defined as complete exclusion of the aneurysm after secondary intervention. An endoleak was defined as radiologic evidence of blood flow outside the stent graft and was classified as primary (diagnosed within 30 days of endovascular repair) or secondary (diagnosed more than 30 days after intervention). Malperfusion was defined as radiologic signs of hypoperfusion in the visceral region, renal arteries, lower extremities. The following were also considered symptoms of malperfusion: clinical signs of an acute abdomen, lactic acidosis, oliguria or aneuria, increasing values on renal functions tests, abnormal pulse examination, paresthesia, or paralysis.

\section{Statistical Analysis}

Continuous data are presented as the median and interquartile range (25th to 75 th percentiles). Discrete data are given as counts and percentages. Time-dependent Cox regression analysis was performed to assess the potential risk factors on overall outcome. Only preoperative variables were considered for inclusion in the model based on the rationale of a preoperative risk assessment. The results of the regression model are given as the odds ratio and $95 \%$ confidence intervals. Regression diagnostics and overall model fit were performed according to standard procedures. Calculations were performed using the Statistical Package for Social Sciences, for Mac OsX, version 16.0 (SPSS, Chicago, Ill).

\section{RESULTS \\ In-Hospital Results}

Technical feasibility with deployment of the stent graft device at the targeted position was $100 \%$ (Figure 2). Primary success was achieved in $23(85 \%)$ of 27 patients. Four patients developed an early type Ia endoleak (15\%). One underwent conversion to conventional surgery because no additional interventional option was possible. Two other patients had proximal stent graft extension with sealing of the endoleak site in 1 patient. The fourth patient had undergone stent graft placement in an emergency setting with malperfusion of the visceral organs. Decompression of the true lumen was achieved but the patient had a type 1a endoleak. Owing to his problematic conditions, no additional intervention was made, and the patient is now under surveillance with no additional increase in the aortic diameter. The rate of persistent primary endoleak was $8 \%$ (Table 3 ). Vessel access was achieved through the left or right common femoral artery in all patients. The mean aortic diameter at intervention was $48 \pm 13 \mathrm{~mm}$ and the mean covered length of the descending aorta was $140 \pm 47 \mathrm{~mm}$. Of the 29 
TABLE 1. Demographics and clinical characteristics $(n=29)$

\begin{tabular}{lc}
\multicolumn{1}{c}{ Variable } & Value \\
\hline Men & $22(76)$ \\
Age (yr) & \\
Mean & 61 \\
Range & $22-78$ \\
Comorbidity & \\
Hypertension & $25(86)$ \\
Marfan syndrome & $1(3)$ \\
COPD & $4(14)$ \\
Coronary artery disease & $8(27)$ \\
Diabetes & $4(14)$ \\
Previous aortic surgery & $5(17)$ \\
ASA score $>$ IV & $21(72)$ \\
\hline $\begin{array}{l}\text { Data presented as number of patients, with percentages in parentheses, unless other- } \\
\text { wise noted. COPD, Chronic obstructive pulmonary disease; ASA, American Society } \\
\text { of Anesthesiologists. }\end{array}$
\end{tabular}

patients, 19 were treated with 1 endoprosthesis, 9 with 2 , and 1 with 3 (Table 3). The left subclavian artery was intentionally totally covered by the stent graft in 1 patient $(3 \%)$. No symptoms of ischemia of the left arm or subclavian steal syndrome requiring secondary revascularization were identified during the initial hospitalization.

A total of 17 patients presented with signs of malperfusion. Of these, 8 patients had malperfusion of the renal arteries, 5 had malperfusion of the lower extremity, and 4 had malperfusion of the celiac trunk or superior mesenteric artery. Additional intraprocedural stenting was necessary in 6 patients to alleviate persistent obstruction of the true lumen by extension of the intimal flap beyond the vessel's origin. Three patients required stenting of the celiac trunk, two of the superior mesenteric artery, and one of the left renal artery.

The overall hospital mortality was $17 \% \pm 7 \%(95 \%$ confidence interval) with 2 intraprocedural deaths from aortic rupture and retrograde dissection into the ascending aorta. The causes of the remaining 3 hospital deaths included multiorgan failure in 2 patients and aortic rupture in 1 patient. The 2 patients who died of multiorgan failure had additional intraprocedural stenting of the superior mesenteric artery. Malperfusion, however, persisted with signs

TABLE 2. Indication for intervention and extent of dissection $(n=29)$

\begin{tabular}{lc}
\hline \multicolumn{1}{c}{ Indication for intervention } & Patients (n) \\
\hline Malperfusion & $17(59)$ \\
Aortic rupture & $5(17)$ \\
Persistent ongoing pain & $5(17)$ \\
Refractory hypertension & $2(7)$ \\
Extent of dissection & \\
Descending only & $7(24)$ \\
Descending to celiac axes & $5(17)$ \\
Descending to aortic bifurcation & $5(17)$ \\
Descending to iliac arteries & $12(42)$ \\
\hline
\end{tabular}

Data in parentheses are percentages.

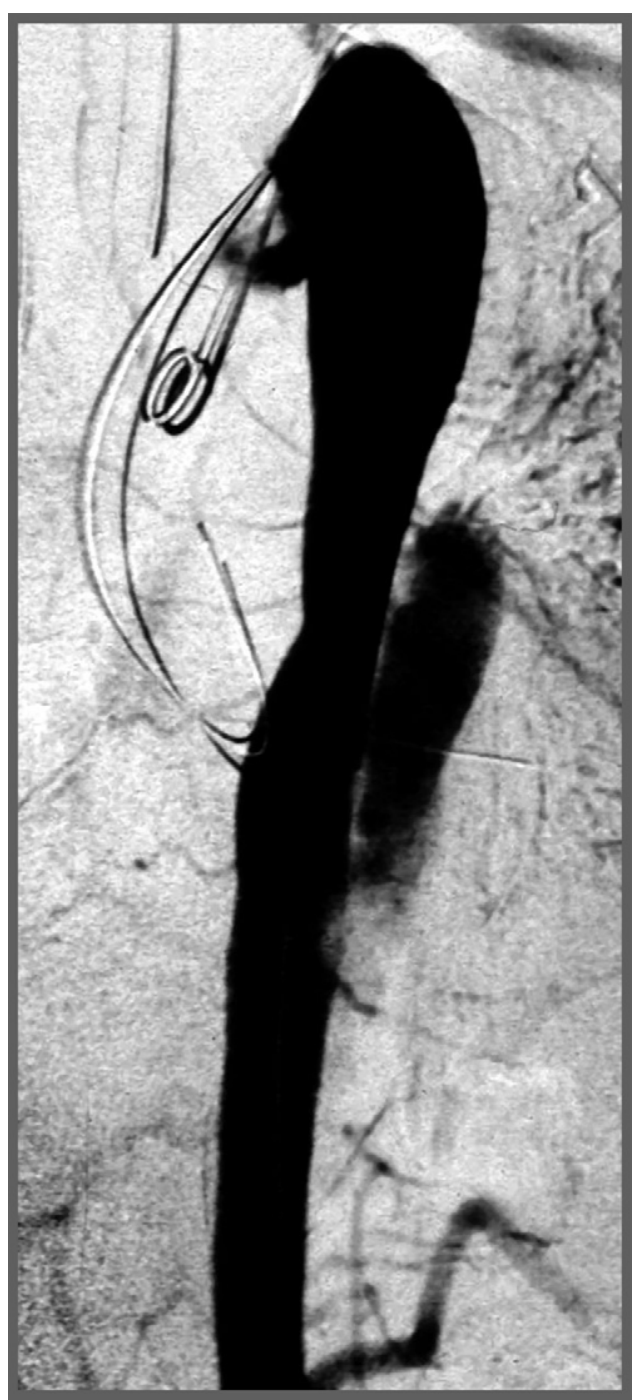

FIGURE 1. Preoperative computed tomography scan of a malperfusion syndrome due to acute complicated type B dissection.

of bowel necrosis. After multisegmental bowel resection, both patients died during their hospital stay. None of the treated patients who were younger than 52 years died during the hospital stay and had a 1- and 5-year survival rate of $100 \%$ and $87 \%$, respectively. In contrast, patients older than 72 years had a hospital mortality rate of $29 \%$ with worse long-term outcomes (Figure 4). Local injury with reconstruction of the femoral artery was observed in 2 patients $(7 \%)$.

Three patients (11\%) developed new neurologic complications ( 2 strokes and 1 transient ischemic attack).

\section{Follow-Up}

The mean follow-up period for hospital survivors was 53 \pm 41 months, with an overall mortality rate of $25 \%(6 / 24$ patients). Of the 6 late deaths, $2(8 \%)$ were aortic related 


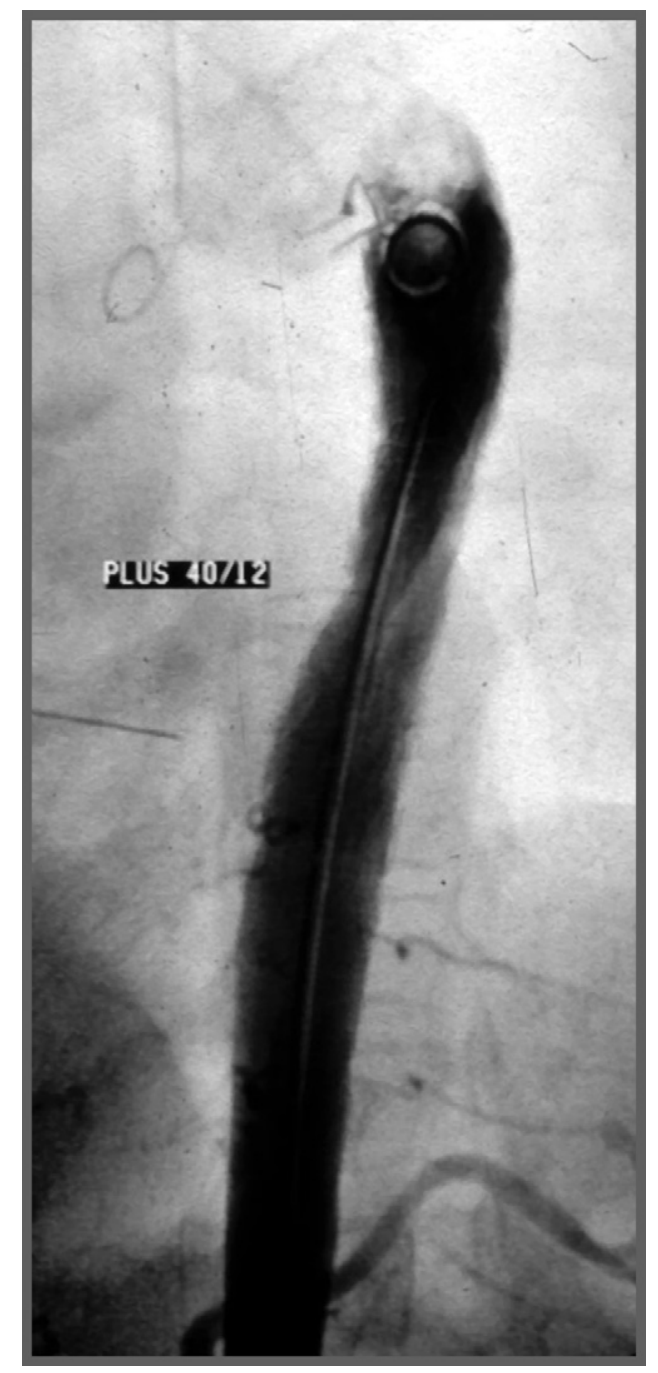

FIGURE 2. Postinterventional computed tomography scan.

and the remaining were related to other causes (Table 4). The actuarial survival at 1 and 5 years was $79 \%$ and $61 \%$, respectively (Figure 3). Two patients who survived the procedure developed a late endoleak and both were successfully treated by additional stent graft extensions. Freedom from treatment failure at 1 and 5 years (including

TABLE 3. Intraprocedural results $(n=29)$

\begin{tabular}{lc}
\hline \multicolumn{1}{c}{ Variable } & Value \\
\hline Length of covered aorta (mm) & $140 \pm 47$ \\
Distance from left subclavian artery & $44 \pm 14$ \\
$\quad$ to stent (mm) & \\
Stent grafts used (n) & \\
1 & $19(65)$ \\
2 & $9(32)$ \\
3 & $1(3)$ \\
\hline
\end{tabular}

Data presented as mean \pm standard deviation or numbers of patients, with percentages in parentheses.
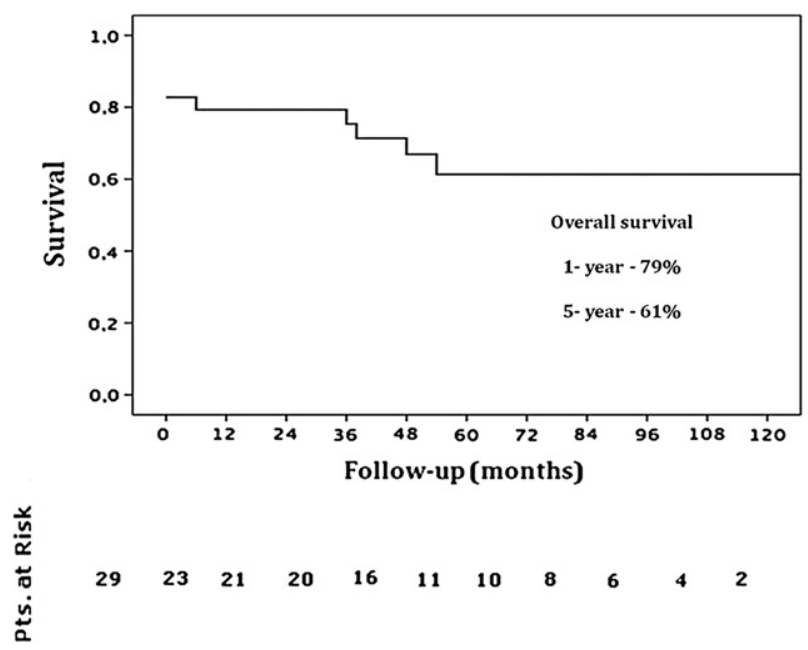

FIGURE 3. Overall survival.

reintervention, aortic rupture, device-related complication, aortic-related death, or sudden, unexplained late death) was $82 \%$ and $77 \%$, respectively (Figure 5). From the latest computed tomography scan, complete thrombosis of the false lumen just distally of the stent graft was observed in $62 \%$ of all surviving patients and partial or patent false lumen was seen in $21 \%$ and $17 \%$ of the remaining cases, respectively. Additionally, in the 15 patients with complete thrombosis of the false lumen, the mean false lumen diameter between the first and last follow-up examination decreased in 8 patients $(54 \%)$, was stable in $5(33 \%)$, and increased slightly in $2(13 \%)$. In contrast, the false lumen increased in 3 patients $(60 \%)$ and remained stable in 2 patients $(40 \%)$, in whom the false lumen was partially patent. In those 4 patients, in whom the false lumen was fully patent, the diameter increased in 2 patients $(50 \%)$, remained stable in $1(25 \%)$, and increased in 1 patient $(25 \%)$.

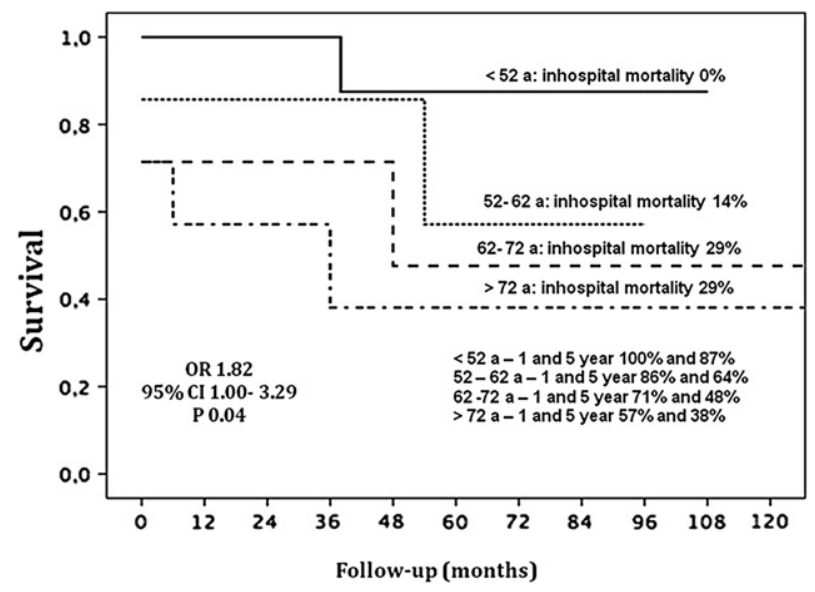

FIGURE 4. Overall survival according to age. 
TABLE 4. Causes of late mortality

\begin{tabular}{lc}
\hline \multicolumn{1}{c}{ Cause } & Patients (n) \\
\hline Aortic related & \\
$\quad$ Aortic rupture & $2(8)$ \\
Nonaortic related & \\
Bronchial carcinoma & $1(4)$ \\
Stroke & $1(4)$ \\
Myocardial infarction & $1(4)$ \\
Pneumonia & $1(4)$ \\
\hline Data in parentheses are percentages. &
\end{tabular}

\section{DISCUSSION}

Transluminal placement of endovascular stent grafts has been used in the past 2 decades as a treatment of descending thoracic aortic pathologic findings such as degenerative aneurysm, acute or chronic dissection, and penetrating ulcer or intramural hematoma. ${ }^{7,12}$ This innovative treatment modality has gained increased acceptance across the world, with excellent short-term results, and offers the possibility of treating patients who are not candidates for conventional surgical procedures because of their existing comorbidities. Furthermore, progress has been achieved with regard to the safety and effectiveness of stent grafts in the repair of thoracic aneurysms. ${ }^{10}$

Since the first reports describing the treatment of acute type B aortic dissection with stent graft technology, optimism was raised for improved early and late survival. ${ }^{1,14}$ The concept of this procedure was directed toward sealing of the proximal intimal tear, redirecting flow into the true lumen, and promoting depressurization and thrombosis of the false lumen. In addition, such an approach can effectively treat malperfusion syndrome by reestablishing side branch flow in dynamic obstruction. ${ }^{15,16}$ Furthermore, the primary stent graft procedure might be used as a bridge to conventional surgery, once the patient's renal and hepatic problems have

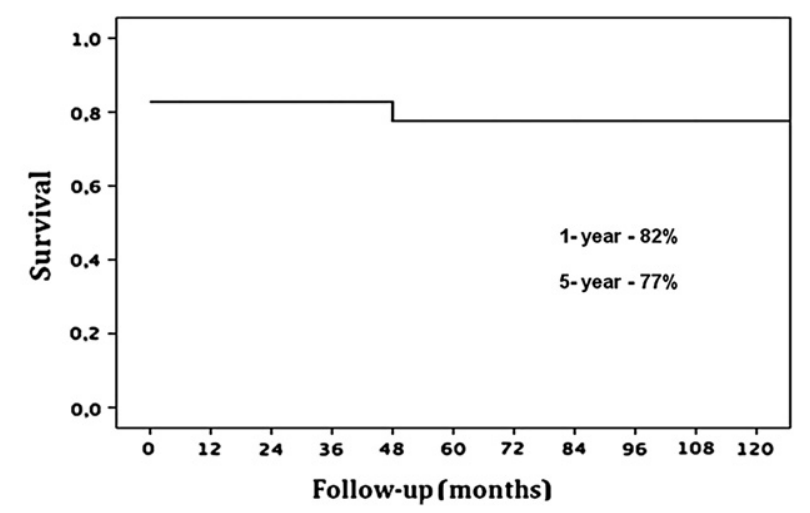

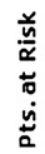

29

$23 \quad 21$

20

16

11

8

6

2

FIGURE 5. Freedom from treatment failure resolved and bowel ischemia has been reversed. Increasing experience with endovascular treatment in the spectrum of aortic dissection has confirmed both the feasibility and the usefulness, especially in unstable patients, with encouraging early and midterm results. ${ }^{17}$

Our results have indicated that stent graft placement is a feasible and effective approach in the treatment of acute complicated type B dissection. Most recent published reports contain both complicated and uncomplicated cases, as well as mixed cases of acute and chronic dissection. ${ }^{18-22}$ However, it was well demonstrated recently that controlling hypertension and pain in the initial phase is the optimal approach for the treatment of uncomplicated aortic type B dissection. ${ }^{3}$ Therefore, in patients with life-threatening complications of acute type B dissection, stent graft placement could emerge as the most valid treatment option with the primary goal of alleviating severe malperfusion complications and aortic rupture and stabilizing the patient in the first phase.

Hospital mortality in our series was $17 \%$, similar to published reports with a range of $3 \%$ to $20 \%{ }^{17,19,23}$ This mortality rate corresponds to the reported mortality for medically treated patients in historic controls and is better than the expected open surgical mortality for these patients. Effectively, endovascular techniques have shifted these patients from the greater mortality associated with complicated dissection treated surgically to lower mortality. Nienaber and colleagues ${ }^{13}$ even reported in 1999 an early mortality of $0 \%$ for 12 patients with descending aortic aneurysm. However, in their series, the patient profiles and selection were different. Endovascular stent grafting was not performed as an emergency treatment in a life-threatening situation. This might explain in part the difference in mortality. Nevertheless, the 3 stent graft-related deaths have demonstrated the difficulties of conforming the device to the curvature of the aortic arch. Although some improvements have been seen with more recent generations of the endoprosthesis, this problem still escapes solution. Additional technological developments are needed to obtain a stent graft that aligns well in the arch and provides good fixation without traumatizing the friable aortic wall.

Another important aspect in this clinical setting is that stent graft placement over the intimal tear can prevent the development of an aneurysm by facilitating complete thrombosis of the false lumen. Therefore, to achieve satisfactory mid- and long-term outcomes, the distance between the left subclavian artery and the primary intimal entry tear is important. If there is a sufficient "landing zone" and full coverage of the proximal intimal tear can be achieved with the stent graft, full thrombosis of the false lumen at the level of the stent graft device can be expected. In contrast, if the proximal intimal tear is very close to the left subclavian artery and the stent graft needs to be placed in the distal aortic arch with coverage of the left subclavian artery, the risk of a type 1a endoleak developing is increased. Furthermore, 
this imperfect stent graft position can lead to aortic rupture by either erosion of the arterial wall or failure of the proximal seal provided by the stent graft. Moreover, the misalignment of stent grafts in angulated aortic arches, together with the high hemodynamic forces in this region, can cause structural instability of the stent graft and its subsequent collapse. ${ }^{24}$ In the present series, the mean distance between the left subclavian artery and the first stent graft was $44 \mathrm{~mm}$, reflecting a sufficient "landing zone" in most of the treated patients.

Neurologic complications, especially paraplegia, remain the most devastating complications after stent graft placement or surgical repair of type B aortic dissection. Occlusion of numerous critical intercostal arteries with stent grafts is widely believed to be responsible for the increased risk of paraplegia. The present study has shown that the overall risk of neurologic complications in patients treated with stent grafting was $11 \%$, with none developing paraplegia. In addition, our data have demonstrated that stroke occurred in $7 \%$ of the patients after stent graft treatment, significantly greater than that reported in other series. ${ }^{17}$ We believe this was related to the older age of the patients who developed this complication (75 and 78 years) and the difficult advancement and manipulation of the guidewire or stent graft delivery system within the aortic arch.

Complete thrombosis of the false lumen distally to the stent graft was observed in $61 \%$ of our patients. This is a rate consistent with the findings from other studies that reported a rate of false lumen thrombosis in that region of $60 \%$ to $70 \%{ }^{25,26}$ Also, a significant reduction of the false lumen diameter was achieved in these patients.

The rate of primary endoleaks after endovascular repair of variant thoracic aortic lesions was reported to be $11 \%$ to $20 \%{ }^{27,28}$ In our patient group, the rate of primary endoleak was $15 \%$. With additional proximal stent graft extension and 1 surgical conversion, the rate of persistent primary endoleak decreased to $8 \%$. Overall, during the follow-up period, an additional endovascular procedure was performed successfully in 2 of 24 patients with persistent primary endoleak.

The present review had some limitations. Because of its retrospective nature, there was no control over the inclusion criteria for the endovascular procedure. The lack of a randomized or concurrent control group precluded direct comparison with conventional open repair or exclusive medical therapy. In addition, to make any significant conclusions regarding the durability of endovascular therapy, it will be necessary to obtain longer term follow-up data. The currently available data on follow-up outcomes fail to provide precise morphologic information and, instead, focused on clinical endpoints. Therefore, additional investigation is crucial to assess the applicability and prognostic potential of acute stent graft placement in patients with complicated thoracic aortic dissection.
In conclusion, endovascular treatment of thoracic aortic disease with the Talent stent graft performed at highvolume referral centers is associated with acceptable early morbidity and mortality rates in this high-risk patient population. Most of all, closure of the entry tear and stabilization of the true lumen presents a promising alternative treatment option to conventional surgery for relief of lifethreatening dissection-related complications. Follow-up data indicate a substantial durability of the procedure with an acceptable freedom from stent graft-related death and secondary interventions. Although preliminary data suggest that stent graft repair might ultimately become the treatment of choice for these relatively ill patients, long-term surveillance will be crucial to discover the complications unique to thoracic endovascular interventions. Most importantly, comparative clinical trials are clearly needed to clarify the role of stent graft repair in the setting of acute complicated type B aortic dissection.

\section{References}

1. Erbel R, Alfonso F, Boileau C, Dirsch O, Eber B, Haverich A, et al., Task Force on Aortic Dissection, European Society of Cardiology. Diagnosis and management of aortic dissection. Eur Heart J. 2001;22:1642-81.

2. Nienaber CA, Eagle KA. Aortic dissection: new frontiers in diagnosis and management: part II: therapeutic management and follow-up. Circulation. 2003;108: $772-8$

3. Nienaber CA, Rousseau H, Eggebreecht H, Kische S, Fattori R, Rehders TC, et al. Randomized comparison of strategies for type B aortic dissection: the INvestigation of STEnt Grafts in Aortic Dissection (INSTEAD) trial. Circulation. 2009;120:2519-28.

4. Crawford ES, Mizrahi EM, Hess KR, Coselli JS, Safi HJ, Patel VM. The impact of distal aortic perfusion and somatosensory evoked potential monitoring on prevention of paraplegia after aortic aneurysm operation. J Thorac Cardiovasc Surg. 1988;95:357-67.

5. Kouchoukos NT, Wareing TH, Izumoto H, Klausing W, Abboud N. Elective hypothermic cardiopulmonary bypass and circulatory arrest for spinal cord protection during operations on the thoracoabdominal aorta. J Thorac Cardiovasc Surg. 1990;99:659-64.

6. Brandt M, Hussel K, Walluscheck KP, Böning A, Rahimi A, Cremer J. Early and long-term results of replacement of the descending aorta. Eur J Vasc Endovasc Surg. 2005;30:365-9.

7. Dake MD, Miller DC, Semba CP, Mitchell RS, Walker PJ, Liddell RP. Transluminal placement of endovascular stent-grafts for the treatment of descending thoracic aortic aneurysms. $N$ Engl J Med. 1994;331:329-34.

8. Inoue KI, Iwase T, Sato M, Yoshida Y, Tanaka T, Kubota Y, et al. Clinical application of transluminal endovascular graft placement for aortic aneurysms. Ann Thorac Surg. 1997;63:522-8.

9. Mitchell RS, Miller DC, Dake MD, Semba CP, Moore KA, Sakai T. Thoracic aortic aneurysm repair with an endovascular stent graft: the first generation. Ann Thorac Surg. 1999;67:1971-4.

10. Mitchell RD, Dake MD, Semba CP, Fogarty TJ, Zarins CK, et al. Endovascular stent graft repair of thoracic aortic aneurysms. J Thoracic Cardiovasc Surg. 1996; 111:1054-9.

11. Czermak BV, Waldenberger P, Perkmann R, Rieger M, Steingruber IE, Mallouhi A, et al. Placement of endovascular stent grafts for emergency treatment of acute disease of the descending thoracic aorta. AJR Am J Roentgenol. 2002;179:337-45.

12. Fattori R, Nienaber CA, Rousseau H, Beregi JP, Heijmen R, Grabenwoger M, et al., Talent Thoracic Retrospective Registry. Results of endovascular repair of the thoracic aorta with the Talent Thoracic stent graft: the Talent Thoracic Retrospective Registry. J Thorac Cardiovasc Surg. 2006; 132:332-9.

13. Nienaber CA, Fattori R, Lund G, Dieckmann C, Wolf W, von Kodolitsch Y, et al. Nonsurgical reconstruction of thoracic aortic dissection by stent-graft placement. N Engl J Med. 1999;340:1539-45. 
14. Dake MD, Kato N, Mitchell RS, Semba CP, Razavi MK, Shimono T, et al. Endovascular stent-graft placement for the treatment of acute aortic dissection. $N$ Engl J Med. 1999;340:1546-52.

15. Greenberg R. Treatment of aortic dissections with endovascular stent grafts. Semin Vasc Surg. 2002;15:122-7.

16. Nienaber CA, Kische S, Zeller T, Rehders TC, Schneider H, Lorenzen B, et al. Provisional extension to induce complete attachment after stent-graft placement in type B aortic dissection: the PETTICOAT concept. J Endovasc Ther. 2006;13: 738-46.

17. Eggebrecht $H$, Nienaber $C A$, Neuhäuser $M$, Baumgart $D$, Kische $S$, Schmermund A, et al. Endovascular stent-graft placement in aortic dissection: a meta-analysis. Eur Heart J. 2006;27:489-98.

18. Kische S, Ehrlich MP, Nienaber CA, Rousseau H, Heijmen R, Piquet P, et al. Endovascular treatment of acute and chronic aortic dissection: midterm results from the Talent Thoracic Retrospective Registry. J Thorac Cardiovasc Surg. 2009;138: 115-24.

19. Xiong J, Jiang B, Guo W, Wang SM, Tong XY. Endovascular stent graft placement in patients with type B aortic dissection: a meta-analysis in China. J Thorac Cardiovasc Surg. 2009; 138:865-72.

20. Dialetto G, Covino FE, Scognamiglio G, Manduca S, Della Corte A, Giannolo B, et al. Treatment of type B aortic dissection: endoluminal repair or conventional medical therapy? Eur J Cardiothorac Surg. 2005;27:826-30.

21. White RA, Miller DC, Criado FJ, Dake MD, Diethrich EB, Greenberg RK, et al., Multidisciplinary Society for Vascular Surgery Outcomes Committee. Report on the results of thoracic endovascular aortic repair for acute, complicated, type B aortic dissection at 30 days and 1 year from a multidisciplinary subcommittee of the Society for Vascular Surgery Outcomes Committee. J Vasc Surg. 2011; 53:1082-90.

22. Shu C, He H, Li QM, Li M, Jiang XH, Luo MY. Endovascular repair of complicated acute type-B aortic dissection with stent graft: early and mid-term results. Eur J Vasc Endovasc Surg. 2011;42:448-53.

23. Schoder M, Czerny M, Cejna M, Rand T, Stadler A, Sodeck GH, et al. Endovascular repair of acute type B aortic dissection: long-term follow-up of true and false lumen diameter changes. Ann Thorac Surg. 2007;83:1059-66.

24. Melissano G, Tshomba Y, Civilini E, Chiesa R. Disappointing results with a new commercially available thoracic endograft. J Vasc Surg. 2004;39:124-30.

25. Kato M, Matsuda T, Kaneko M, Kuratani T, Mizushima T, Seo Y, et al. Outcomes of stent-graft treatment of false lumen in aortic dissection. Circulation. 1998;98: II305-12.

26. Duebener LF, Lorenzen P, Richardt G, Misfeld M, Nötzold A, Hartmann F, et al Emergency endovascular stent-grafting for life-threatening acute type B aortic dissections. Ann Thorac Surg. 2004;78:1261-7.

27. Taylor PR, Gaines PA, McGuinness CL, Cleveland TJ, Beard JD, Cooper G, et al. Thoracic aortic stent grafts-early experience from two centres using commercially available devices. Eur J Vasc Endovasc Surg. 2001;22:70-6.

28. Criado FJ, Clark NS, Barnatan MF. Stent graft repair in the aortic arch and descending thoracic aorta: a 4-year experience. J Vasc Surg. 2002;36:1121-8. 